\title{
La tercera revolución tecnológica
}

\author{
Lourdes Romero Navarrete
}

HERNÁN SALAS QUINTANAR, 2002

\section{Antropología, estudios rurales y cambio social. La globalización en la región lagunera}

Universidad Nacional Autónoma de México, México.

E

Iimpacto de la globalización sobre la diversidad cultural ha constituido, sin duda, un acicate al renovado interés de las ciencias sociales por el tema de la identidad. La obra de Hernán Salas Quintanal, Antropología, estudios rurales y cambio social. La globalización en la región lagunera, es representativa de las respuestas que está ofreciendo la antropología al desafío que implica entender uno de los componentes sociales más vulnerables ante el proceso de globalización: la identidad social.

LOURDES Romero NAVARRETE: CIESAS Programa Noreste.

Desacatos, núm. 11, primavera 2003, pp. 181-184.
A la par que los procesos identitarios se han convertido en uno de los espacios de expresión más dinámicos de las transformaciones actuales generadas por la globalización, ésta ha obligado a las ciencias sociales a criticar los paradigmas tradicionales y a incorporar nuevos conceptos, metodologías y esquemas explicativos. La globalización, apunta el autor, trasciende la dimensión espacio-temporal que hasta hace unas décadas definía el marco de las interacciones sociales, $y$ ha impactado de tal manera el pensamiento científico occidental, que la dualidad y dicotomías paradigmáticas del método científico tradicional, en tanto son mecanismos que obligan a reconocer fronteras y límites precisos, resultan inoperantes para analizar procesos exactamente contrarios. Bajo esta perspectiva, profusamente tratada en los dos primeros capítulos, la globalización obliga a otorgar un papel decisivo a los vínculos y continuidades entre fenómenos, procesos y contextos sociales, por lo que el desafío científico consiste en desterritorializar, eliminar fronteras entre las disciplinas y entre los hechos de la realidad, tal como ocurre con el proceso de globalización. Esta propuesta, sin embargo, invita a preguntarse si la complejización de la realidad derivada de la globalización tiene un fundamento epistemológico, o bien, si tal complejidad lo que demanda es una dinámica diferente en la inter y multidisciplinariedad. Resulta incontrovertible que la globalización es un proceso histórico que afecta en mayor o menor medida a todos los habitantes del planeta.

Los mecanismos de elaboración y reelaboración de identidades sociales en La Laguna, detonados por el proceso de globalización, resulta para Salas un campo propicio para enfocar a las 
sociedades rurales desde una metodología obligadamente distinta a la que tradicionalmente ha caracterizado el quehacer antropológico. La observación de la alteridad a partir de rasgos que se consideraban propios de una sociedad cerrada, identificada casi siempre por rasgos de carácter étnico, resulta inoperante al tratar a los productores lecheros de La Laguna insertos en la economía global, para quienes la externalidad es el elemento a partir del cual se construye la identidad.

La hipótesis de la cual parte Salas consiste en considerar que la globalización ha creado en La Laguna condiciones para el surgimiento de una cultura lechera, es decir, de una sociedad que se desenvuelve y constituye en torno de la producción del lácteo, y que se expresa en un estilo de vida, entendido como un "ordenamiento en el espacio y en el tiempo", donde se transforman prácticas sociales, formas de habitar y de ser "en un espacio definido por lo vinculante y lo histórico (tradición), que ordena y proporciona sentido y orientación a la vida social". La globalización ha afectado económica, social y culturalmente a los productores ganaderos de la región, ninguno de los cuales está organizado a partir de su etnicidad, sino por los rasgos culturales construidos como resultado de una incorporación económica artificial, es decir, impuesta por factores externos. Bajo esta premisa, la construcción de identidades, la permanencia y el cambio social, dependen de una multiplicidad de formas y escalas de interacción con el exterior. Para el autor esto impide la formación de grupos de identidad aislados o

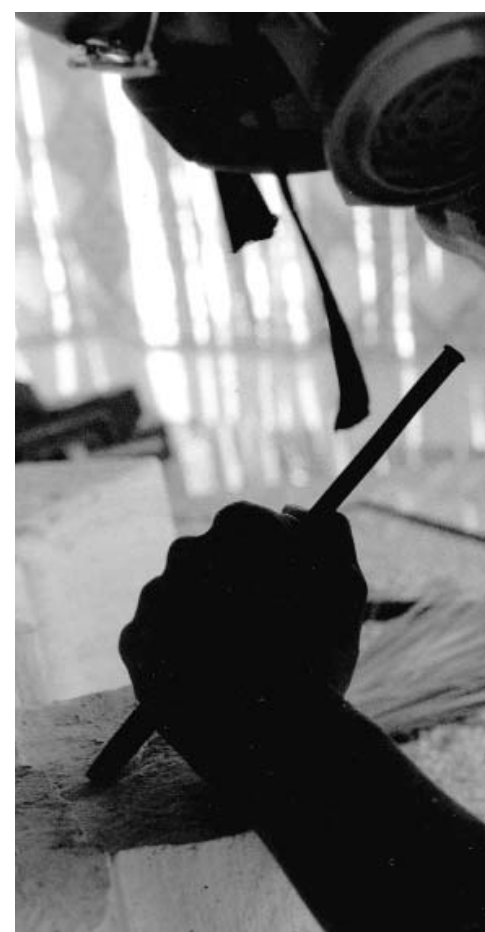

De la serie: Alto, mujeres trabajando, 2003 / Roxana Acevedo

diferenciados, lo que resulta identificable, en cambio, son tendencias identitarias en las que se sintetiza lo global-local, local-local, regional-nacional-global.

En el desarrollo de este planteamiento se identifican cuatro ejes de investigación: el proceso de modernización e innovación tecnológica (donde ambas participan como agentes del cambio); la lógica del mercado a través del cual se instrumenta la modernización; las asimetrías bajo las que se realiza y que al mismo tiempo genera esa lógica mercantil; y el impacto que tienen estos factores en las identidades locales.

En la descripción del marco histórico mundial y regional en el que se desenvuelve la modernización e innovación tecnológica de la producción lechera, abordada por Salas en tres capítulos intermedios, el autor hace referencia a la gradual complejización económica que ha experimentado la actividad ganadera a lo largo del tiempo, así como de las implicaciones ideológicas correspondientes a dichos cambios. El ganado, como ocurre con otros recursos empleados por el hombre, presenta históricamente una connotación distinta en la relación hombre-Naturaleza. Desde un pastoreo que prominentemente atribuyó un valor de uso a los animales domesticados, hasta la prevalencia de valores mercantiles introducidos por el esquema capitalista de producción. Desde una visión del mundo campesino tradicional que atribuye un significativo valor simbólico a la triada hombreanimal-Naturaleza, hasta una economía campesina inmersa en el proceso de acumulación capitalista en la que persisten estos elementos, pero ahora influidos por el principio privatizador y por una concepción utilitarista de los recursos del medio. Este tipo de valores han sido transformados por la globalización actual de tal forma que se han desvanecido las líneas que otrora definían grupos identitarios compactos, dando lugar a la construcción de sistemas de valores compartidos donde lo tradicional se conjuga con lo moderno, y lo local con lo global.

Este nuevo panorama, como lo describe Salas, tiene su detonante en la llamada tercera revolución tecnológica de la que aún no acabamos de percibir su culminación y que se caracteriza por vincular innovaciones en el ramo 
de la informática, telecomunicaciones, biotecnología - entre otras - con formas organizacionales ad hoc a la dinámica de un sistema ampliamente interconectado. En conjunto, estos elementos han modificado de manera sustantiva las condiciones espacio-temporales en las que se venía desarrollando el proceso productivo (producción, circulación y consumo). Ahora, las empresas poseedoras del gran capital y los Estados promotores de políticas neoliberales generan una simultaneidad productiva a través de la transnacionalización de acciones y procesos, que acaba por relacionar a todas las naciones del planeta, impactando severamente el marco de las interacciones culturales.

Esta transnacionalización genera por sí misma un proceso de homogeneización en los más diversos sentidos que en el discurso, se afirma, está encaminado a la estandarización en el consumo y a la generalización de mayores niveles de bienestar, pero, como apunta Salas, las condiciones en las que se desarrolla la economía globalizada dan lugar a una profundización de las asimetrías económicas y sociales. En efecto, el ritmo con el que son introducidos los cambios en la producción económica, la concordancia o no de los elementos locales con los intereses de las compañías y capitales transnacionales, y por consiguiente con la variabilidad de ventajas comparativas según la ubicación, etc., impiden un desarrollo equilibrado, convirtiéndose, en cambio, en elementos de dispersión, fragmentación y exclusión social, características que se reflejan en la vida económica y en las respuestas identitarias locales.

El tránsito de la agroindustria a la globalización, explica Salas, se produjo en la década de los ochenta, en medio de la crisis desencadenada por la concurrencia de factores como la falta de liquidez, el crecimiento desproporcionado de la deuda de los países del tercer mundo y el colapso de los precios de los cereales, el cual afectó especialmente a Estados Unidos. A través de la apertura financiera - que el propio gobierno estadounidense impulsóel Fondo Monetario Internacional y el Banco Mundial, canalizaron los excedentes de cereales de Estados Unidos hacia los países latinoamericanos, que de esta forma vieron trastocada la política de autosuficiencia alimentaria que venían promoviendo años atrás, forzándose a depender súbitamente del abasto externo.

Este mecanismo reproducido en un marco de continuas crisis financieras y de interrelaciones cada vez más cerradas (reforzado por el TLC en el caso de México), ha tenido en estos países consecuencias muy claras en su política alimentaria. Ésta deja de ser controlada por los Estados nacionales para delegar en las compañías agroindustriales de origen transnacional, la mayor parte de las acciones relacionadas con la producción de alimentos, tales como tipos de cultivo, naturaleza de los insumos (transgénicos, pesticidas, etc.), creación de modas alimentarias (necesidades dietéticas generadas por la mercadotecnia), entre otros.

¿Cómo ha impactado este escenario mundial a la región lagunera? Salas afirma que La Laguna ha sido un espacio donde la economía global ha encontrado fuertes posibilidades de articulación por diversas razones, una de ellas histórica. En efecto, el patrón de acumulación capitalista y, como una de sus características primordiales, la modernización tecnológica, han sido una constante en la economía regional. Despegó en la segunda mitad del siglo XIX, justamente como resultado de la penetración de capitales foráneos (regiomontanos, de la capital del país, ingleses, alemanes y estadounidenses), los cuales encontraron en la producción algodonera intensiva el elemento detonante de una tradición empresarial muy reconocida en la actualidad. Aquí la innovación tecnológica, las contradicciones sociales y la capacidad de adaptación al cambio son variables que le han distinguido y que constituyen sin duda una fuente de identidad regional. Tradición que atestiguan las corrientes de inmigración extranjera (española, árabe y china, entre otras) y nacionales, en las que se reconoce un sentido emprendedor y que innegablemente han sido fundamentales en la conformación del patrimonio histórico-cultural lagunero.

El origen de la tradición lechera en La Laguna se remonta a los años sesenta del siglo pasado, cuando el Estado impulsó una política de reconversión productiva a fin de paliar los efectos de la crisis provocada por la caída en los precios mundiales del algodón, que, como se mencionó arriba, había sido el eje articulador de la economía regional desde finales del siglo XIX. El gobierno promovió la introducción de cultivos alternativos tales 
como forrajes y cereales e impulsó la creación de una cuenca lechera, misma que ahora se ha convertido en una de las más importantes del país. Desde entonces, afirma Salas, el Estado ha variado su papel de agente económico (financiamiento, apoyos fiscales, construcción de obras de infraestructura hidráulica, etc.), para asumirse, en el contexto globalizante, en promotor de cambios estructurales regionales cuya finalidad ha sido conducir la producción agroindustrial en los términos planteados por la competencia e intereses transnacionales.

Salas encuentra que la modernización se expresa en los productores primarios laguneros a través de la introducción de ganado especializado, inseminación artificial, alimento balanceado, insumos químicos y farmacéuticos, equipos automáticos de ordeña, mejoramiento de infraestructura, y una efectiva integración entre cultivo de forrajes, producción primaria de leche y su industrialización, así como en la distribución y comercialización directa. ${ }^{1}$ En este contexto, el factor de diferenciación entre los productores lecheros es justamente el grado de asimilación de las innovaciones tecnológicas. A partir de él, Salas establece una estructura de

${ }^{1}$ En el caso del productor más importante de La Laguna, la compañía Lala, combina todos estos elementos mediante una serie de filiales organizadas vertical y horizontalmente. No solo fija los controles en la producción mediante la compra de leche cruda a la mayor parte de los establos ejidales y privados, también es dueña de empresas proveedoras de insumos y maquinaria para la producción agrícola y para la industria lechera. productores que funciona solamente como un indicador de la diversidad de actores que componen el sistema lechero y no como una tipología asociada a una identidad definida. El autor reconoce cuatro grupos de productores según su grado de avance tecnológico y organización productiva: a] tecnificado individual, en el que se incluyen los grandes empresarios; b] tecnificado colectivo, integrado por ejidatarios organizados bajo diferentes figuras asociativas y una real capacidad de competencia; c] familiar individual o tradicional, compuesto por productores de traspatio y escasa tecnología; y d] familiar colectivizado, semejante al anterior pero asociados de tal forma que se hallan integrados en condiciones competitivas a la producción regional del lácteo.

Las respuestas culturales de esta diversidad de actores a la globalización es mostrado por Salas a través de los testimonios de diversos productores recogidos en un amplio trabajo de campo. Estas respuestas derivan de los flujos en la información los cuales actúan como operadores de la "destradicionalización", es decir, de los cambios en los parámetros espacio temporales tradicionales para sujetarse a los tiempos y espacios que dicta la simultaneidad con la que ocurren los procesos productivos. Salas menciona a los rancheros y a los ejidatarios como representativos de expresiones identitarias sujetas a la presión de estas fuerzas. En ellos advierte la existencia, por una parte, de una fuerte tradición histórica de modernidad compartida, antes que coahuilense o duranguense, es lagunero, sinónimo de emprendedor, trabajador por definición, hombres y mujeres para los que el desierto es un desafío al que se han enfrentado de manera victoriosa. Sin embargo, existen otros rasgos entre los productores primarios, compartidos sólo por algunos sectores. Así, están los productores involucrados en la competencia demandada por la internacionalización económica, quienes se disputan la primacía en la adopción de tecnologías de punta, o el primer lugar en los mercados locales y nacionales en aras de incorporarse a la competencia internacional, pero también hay segmentos que producen con un bajo nivel de tecnologización y que se caracterizan por su oposición a romper con los parámetros tradicionales de valorización de la leche y con el binomio tradicional hombreanimal. En este grupo hay quienes consideran que las ordeñadoras, los suplementos alimenticios extraídos de los despojos de las propias vacas, etc., son alteraciones que no solamente perjudican la calidad de la leche, también son vistos como prácticas contra natura. En todos los casos, la identidad se resuelve cotidianamente en medio de las innovaciones y persistencias en las que se conjuga la amplia gama de escalas de interacción planteadas por el esquema globalizador.

La internacionalización económica mantendrá el tema de la construcción identitaria en el centro de la discusión antropológica, el estudio de Salas constituye, sin duda, una propuesta innovadora en el análisis de este fenómeno cultural. 